\title{
Therapeutic Effects of BNP in Heart Failure, Good or Bad?
}

\author{
Yuting Zhai ${ }^{1}$, Yanfeng $\mathrm{Ma}^{2}$, Rongsheng $\mathrm{Kan}^{2}$ and Dongye $\mathrm{Li}^{1 *}$ \\ ${ }^{1}$ Institute of Cardiovascular Disease Research, Xuzhou Medical University, PR China \\ ${ }^{2}$ Department of Cardiology, The Affiliated Hospital of Xuzhou Medical University, PR China \\ The first two authors contributed equally to the paper.
}

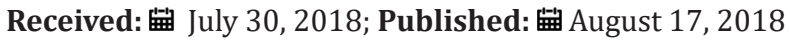

*Corresponding author: Dongye Li, Institute of Cardiovascular Disease Research, Xuzhou Medical University, 84 West Huaihai Road, 221002, China

\begin{abstract}
The natriuretic peptide system plays a critical role in the maintenance of cardiovascular homeostasis. Since the natriuretic peptides were discovered more than 2 decades ago, B-type natriuretic peptide (BNP) and N-terminal proBNP (NT-proBNP) has become the most interesting biomarkers in diagnosis, risk stratification, and management of patients with heart failure (HF). More importantly, with the deepening of understanding of physiological and pathophysiological effects of BNP, increasing biological effects of BNP has been considered to be an attractive approach for treating HF. However, treatment effects of BNP in patients with both acute and chronic HF in various clinical trials have demonstrated different results. The biology of BNP is complex, there are many important issues not yet elucidated. In this review, we will focus on the the diversity of therapeutic effects of BNP in HF and give directions for the future studies.
\end{abstract}

Abbreviations: HF: Heart Failure; BNP: B-type Natriuretic Peptide; CGMP: Cyclic Guanosine Monophosphate; HFREF: Heart Failure with Reduced Ejection Fraction; NT-ProBNP: N-Terminal proBNP; ASCEND-HF: Acute Study of Clinical Effectiveness of Nesiritide in Decompensated Heart Failure; PARADIGM-HF: Prospective Comparison of ARNI with ACEI to Determine Impact on Global Mortalilty and morbidity in Heart Failure

\section{Basic physiology of BNP}

B-type natriuretic peptide (BNP) is a circulating hormone synthesized in the cardiac ventricles in response to ventricular wall stretch resulting from pressure overload [1]. During the processing of BNP production, it is synthesized as a 134-residue preprohormone, which is subsequently cleaved to form a 108-amino-acid biologically inactive prohormone, proBNP. Further cleavage of proBNP results in a physiologically active 32-aminoacid peptide BNP and a biologically inert 76-amino-acid peptide N-terminal proBNP (NT-proBNP) [2]. BNP and NT-proBNP are well-established biomarkers used in diagnosis, risk stratification, and management of patients with HF. They have been applied in clinical practice for more than 10 years and received as the highest classification of recommendation in many medical guidelines for HF $[3,4]$. BNP is not only a gold standard biomarker in HF, it also plays a key role in maintaining circulatory homeostasis.

\section{The Role of BNP in Cardio Protection}

BNP exerts its physiological effects through binding to receptors of the target cells. Three natriuretic peptide receptors (NPR-A, NPR-B, and NPR-C) have been isolated. NPR-A and NPR-B are both transmembrane proteins coupled to guanylyl cyclases. They are capable of increasing the intracellular concentration of the second messenger molecule cyclic guanosine monophosphate (cGMP) after their extracellular domains bind to BNP. BNP exerts most of its biological effects through activating the cGMP dependent signaling cascade. Unlike NPR-A and NPR-B, NPR-C is considered to be a "clearance receptor" for BNP as it mediates the degradation of BNP [5]. The physiological effects of BNP are widespread. It exerts the effects of diuresis, natriuresis, vasodilation, and antagonism of the renin-angiotensin-aldosterone and the sympathetic nervous systems, playing a critical role in the maintenance of cardiovascular homeostasis [1]. Moreover, BNP may also have the actions of antihypertrophy, anti-fibrosis and anti-inflammation in myocardium [6-8].

In HF, it is well established that BNP levels are increased and acts to compensate for HF. However, dysfunction of natriuretic peptides also exits in the setting of HF [9]. The diminished effectiveness of natriuretic peptides may be due to decreased production and increased clearance of natriuretic peptides or reduction of target organ responsiveness. In addition, the counteraction between natriuretic peptides system and other neurohormonal systems may also account for the dysfunction of natriuretic peptides [10]. Because of the above reasons, increasing the beneficial effects of natriuretic peptide signaling through application of exogenous BNP is considered as a promising therapeutic strategy for HF. Various clinical trials have been conducted to test the therapeutic effects of BNP in patients with acute and chronic HF. However, the results of these clinical trials are uncertain. 


\section{Diversity of Therapeutic Effects of BNP in HF Patients}

Based on favorable evidence of hemodynamic and clinical effects shown in various clinical studies [11-13], intravenous infusion of recombinant human BNP (nesiritide) was approved for treating acute decompensated heart failure by the U.S. Food and Drug Administration in 2001 and was subsequently widespread used both in patients with acute HF and in patients with chronic $\mathrm{HF}$ around the world. However, the initial enthusiasm for BNP therapy in HF was diminished because of the ensuing metaanalyses, which indicated that nesiritide was associated with increased risk of death and worsening of renal function $[14,15]$. The subsequent ASCEND-HF (Acute Study of Clinical Effectiveness of Nesiritide in Decompensated Heart Failure) study showed that although intravenous infusion of nesiritide was not associated with a worsening of renal function, it failed to show improvements in clinical outcomes of patients with acute HF [16]. The results of FUSION II (Follow-up Serial Infusions of Nesiritide) trial also suggested no benefit of high-risk patients with chronic HF from long-term therapy with intermittent nesiritide infusion [17].

In addition, both the 2 trials indicated a higher risk of hypotension of BNP therapy. Although these results suggest the need for caution when considering BNP therapy for HF and decrease the attractiveness of treating HF with BNP infusion, studies for therapeutic effects of BNP have never stopped. Chen et al. conducted a small randomized double-blind placebo-controlled proof of concept study to detect safety and efficacy of chronic subcutaneous administration of BNP in patients with systolic HF. They found that subcutaneous BNP administration resulted in evidence of improved LV remodeling, decreased LV filling pressure, and improved Minnesota Living with Heart Failure score in these patients [18]. Very recently, the same group conducted another 2 trials and reported that subcutaneous administration of BNP could improve the cardiorenal response to volume expansion in patients with asymptomatic systolic HF [19] and that BNP therapy could improve diastolic dysfunction in patients with preclinical diastolic dysfunction [20]. Although there are major differences in the characteristics of patients, route of BNP administration and duration of BNP application, which might account for the diversity of therapeutic effects of BNP in patients with HF, the uncertain results indicate that there are many issues not yet elucidated.

It is unclear whether the difference in pharmacokinetic effects between daily subcutaneous administration and intermittent intravenous infusion of BNP may lead to different clinical results. Does the subcutaneously daily use of BNP allow for decreased vasoactive side effects such as hypotension? An additional issue is that routine administration of BNP might not good enough for treating patients with HF. The regulatory mechanism and biological effects of BNP in HF are complex, it is reasonable to strictly monitor the dose of BNP so that not disturbing the homeostasis of the body. As far as we know, BNP altered $\mathrm{Ca} 2+$ cycling by inhibiting SERCA2 a activity and increasing L-type Ca2+ current, resulting in sympathetic overdrive [21]. The proadrenergic effects of BNP may offset its beneficial effects of maintaining hemodynamic stability. Further fundamental studies are needed to confirm the complex pathophysiology of BNP in HF. Apart from direct application of BNP, a less direct method to increase natriuretic peptide signaling has shown benefits in treating patients with HF. The PARADIGM-HF (Prospective comparison of ARNI with ACEI to Determine Impact on Global Mortalilty and morbidity in Heart Failure) trial demonstrated that LCZ696, which was a dual inhibitior of the renin-angiotensinaldosterone system and the neprilysin pathways, improved clinical outcomes in heart failure with reduced ejection fraction (HFrEF) patients [22]. The causes for difference in results between direct application of BNP and the less direct method need further study.

\section{Conclusion}

The key role of the natriuretic peptide system in sustaining circulatory homeostasis has been well recognized. The current uncertainty about the therapeutic effects of BNP in HF can't preclude that the natriuretic peptide system is a good target for treatment of HF. The "bad" results also set the stage for future studies. Additional efforts should aim at deepening understanding of BNP. For example, studies are necessary to confirm the right patient population, answer the question about safety of this drug, develop methods to reduce the proadrenergic side effects and so on. These further explorations will eventually enable a safe and effective treatment of HF with BNP.

\section{Acknowledgement}

This work was supported by the nature science fund of Jiang su province (grant NO. BK20141139).

\section{References}

1. Nishikimi T, Maeda N, Matsuoka H (2006) The role of natriuretic peptides in cardioprotection. Cardiovascular Research 69(2): 318-328.

2. Kambayashi Y, Nakao K, Mukoyama M, Saito Y, Ogawa Y, et al. (1990) Isolation and sequence determination of human brain natriuretic peptide in human atrium. FEBS Lett 259(2): 341-345.

3. Ponikowski P, Voors AA, Anker SD, Bueno H, Cleland JG, et al. (2016) 2016 ESC Guidelines for the diagnosis and treatment of acute and chronic heart failure: The Task Force for the diagnosis and treatment of acute and chronic heart failure of the European Society of Cardiology (ESC). Developed with the special contribution of the Heart Failure Association (HFA) of the ESC. Eur J Heart Fail 18(8): 891-975.

4. Yancy CW, Jessup M, Bozkurt B, Butler J, Casey DE, et al. (2017) 2017 ACC/AHA/HFSA Focused Update of the 2013 ACCF/AHA Guideline for the Management of Heart Failure: A Report of the American College of Cardiology/American Heart Association Task Force on Clinical Practice Guidelines and the Heart Failure Society of America. J Card Fail 23(8): 628-651.

5. Potter LR, Abbey-Hosch S, Dickey DM (2006) Natriuretic peptides, their receptors, and cyclic guanosine monophosphate-dependent signaling functions. Endocr Rev 27(1): 47-72.

6. Tamura N, Ogawa Y, Chusho H, Nakamura K, Nakao K, et al. (2000) Cardiac fibrosis in mice lacking brain natriuretic peptide. Proc Natl Acad Sci USA 97(8): 4239-4244.

7. Silberbach M, Roberts CT Jr (2001) Natriuretic peptide signaling Molecular and cellular pathways to growth regulation. Cell Signal 13(4): 221-231.

8. Rubattu S, Sciarretta S, Valenti V, Stanzione R, Volpe M (2008) Natriuretic peptides: an update on bioactivity, potential therapeutic use, and implication in cardiovascular diseases. Am J Hypertens 21(7): 733-741. 
9. Niederkofler EE, Kiernan UA, O’Rear J, Menon S, Saghir S, et al. (2008) Detection of endogenous B-type natriuretic peptide at very low concentrations in patients with heart failure. Circ Heart Fail 1(4): 258264.

10. Abuzaanona A, Lanfear D (2017) Pharmacogenomics of the Natriuretic Peptide System in Heart Failure. Curr Heart Fail Rep 14(6): 536-542.

11. Colucci WS, Elkayam U, Horton DP, Abraham WT, Bourge RC, et al. (2000) Intravenous nesiritide, a natriuretic peptide, in the treatment of decompensated congestive heart failure. Nesiritide Study Group. N Engl J Med 343(4): 246-253

12. Publication Committee for the VMAC Investigators (Vasodilatation in the Management of Acute CHF) (2002) Intravenous nesiritide vs nitroglycerin for treatment of decompensated congestive heart failure: a randomized controlled trial. JAMA 287(12): 1531-1540.

13. Mitrovic V, Seferovic PM, Simeunovic D, Ristic AD, Miric M, et al. (2006) Haemodynamic and clinical effects of ularitide in decompensated heart failure. Eur Heart J 27(23): 2823-2832.

14. Sackner-Bernstein JD, Kowalski M, Fox M, Aaronson K (2005) Shortterm risk of death after treatment with nesiritide for decompensated heart failure: a pooled analysis of randomized controlled trials. JAMA 293(15): 1900-1905.

15. Aaronson KD, Sackner-Bernstein J (2006) Risk of death associated with nesiritide in patients with acutely decompensated heart failure. JAMA 296(12): 1465-1466.

\section{ISSN: 2574-1241}

DOI: 10.26717/BJSTR.2018.08.001606

Dongye Li. Biomed J Sci \& Tech Res

(c) (P) This work is licensed under Creative

Submission Link: https://biomedres.us/submit-manuscript.php
16. O'Connor CM, Starling RC, Hernandez AF, Armstrong PW, Dickstein K, et al. (2011) Effect of nesiritide in patients with acute decompensated heart failure. N Engl J Med 365(1): 32-43

17. Yancy CW, Krum H, Massie BM, Silver MA, Stevenson LW, et al. (2008) Safety and efficacy of outpatient nesiritide in patients with advanced heart failure: results of the Second Follow-Up Serial Infusions of Nesiritide (FUSION II) trial. Circ Heart Fail 1(1): 9-16.

18. Chen HH, Glockner JF, Schirger JA, Cataliotti A, Redfield MM, et al. (2012) Novel protein therapeutics for systolic heart failure: chronic subcutaneous B-type natriuretic peptide. J Am Coll Cardiol 60(22): 2305-2312.

19. McKie PM, Schirger JA, Benike SL, Harstad LK, Slusser JP, et al. (2016) Chronic subcutaneous brain natriuretic peptide therapy in asymptomatic systolic heart failure. Eur J Heart Fail 18(4): 433-441.

20. Wan SH, McKie PM, Schirger JA, Slusser JP, Hodge DO, et al. (2016) Chronic Peptide Therapy With B-Type Natriuretic Peptide in Patients With Pre-Clinical Diastolic Dysfunction (Stage B Heart Failure). JACC Heart Fail 4(7): 539-547.

21. Zhai Y, Luo Y, Wu P, Li D (2018) New insights into SERCA2a gene therapy in heart failure: pay attention to the negative effects of B-type natriuretic peptides. J Med Genet 55(5): 287-296.

22. McMurray JJ, Packer M, Desai AS, Gong J, Lefkowitz MP, et al. (2014) Angiotensin-neprilysin inhibition versus enalapril in heart failure. $\mathrm{N}$ Engl J Med371(11): 993-1004.

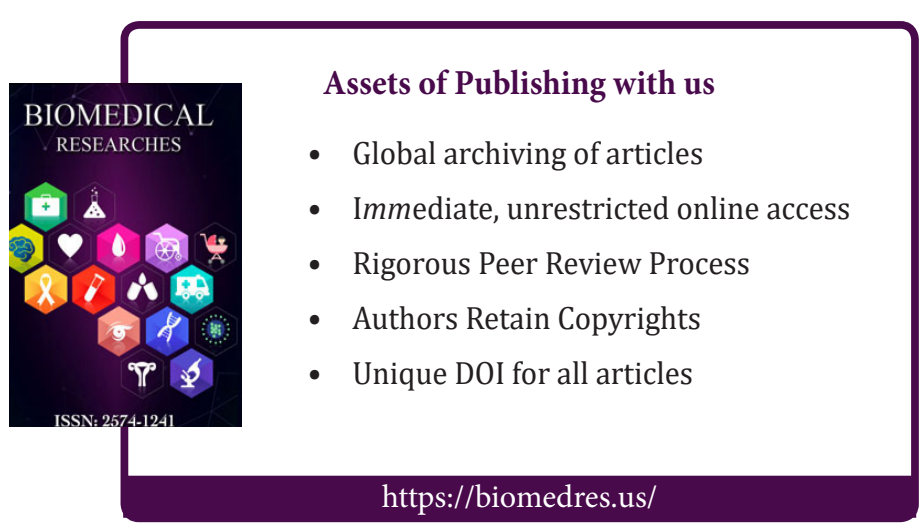

